\title{
MUSIC AND REFRESHMENTS IN PARKS
}

\author{
By Philip H. Goepp, \\ Philadelphia.
}

In matters musical we in America have been wont to take our pattern from European, especially German, traditions, but, strange to say, music for the people in public parks is an exception to this rule. For reasons that are clear, though not patent on the surface, the achievement in this field in America, on distinctly different lines from out-door music on the continent, is a decided advance upon European institutions.

Some three years ago the writer made a cycling tour in Europe, mainly through Germany, crossing north to south from Bremen to Munich, with a special view to the study of the conditions of public music in summer. A startling conclusion of this survey was that nowhere in Germany is the established, regular provision of public music of as high a standard as in the United States in places like Willow Grove Park, Pa., or Ocean Grove, New Jersey. This does not take account of special seasons of opera in Baireuth and Munich, nor of the occasional Mozart festivals in Salzburg, Austria. Whether the cause be a sense of satiety from the high feasts of the winter season or a certain military policy of the government, the fact is clear that almost the only public music in summer in Germany is that of the brass band. It is probably true that the government practises not merely an economy in thus employing its regiment musicians, but that it perceives subtly the wisdom of preserving and encouraging a popular side of the military regime.

Only in one city the writer found an orchestra which alternated with a military band in the Tivoli Garden at Hanover. The effect of this monopoly of the program performed by the brass group and in turn of the taste of the audience is evident. It is to-day a frequent theme and a matter of serious concern to vigilant cities in Germany along with other strange symptoms of the times. Even in the one place where the orchestra alternated with the band, the programs of the former were decidedly inferior to those of the orchestral season at Willow Grove, Pa. To be sure, the writer's survey was not complete, and the time was three years ago. In the (386) 
kursaals of fashionable resorts there may be ambitious orchestral undertakings. But in the field of music, to which the great public has access, the writer's review is probably accurate. A great exception on the European field at large are the promenade concerts at Queen's Hall, London, under Mr. Wood, which are a successful popular institution of very high standard. A symphony concert program of the best possible design is regularly supplemented by a group of ballads performed by at least two singers-a model which it is well to bear in mind in America.

The question of refreshments is closely bound up with that of public musical entertainment in the open season. A study of the conditions, especially in Europe, discloses a curious, close relation between the two; whether this relation springs from past association or from inherent reasons is difficult and perhaps useless to determine. The question of refreshments can never be left out of sight in the whole consideration of public music. At the outset, however, it may be well to discuss the form of music that seems most desirable.

Consider the attitude of an average audience, gathered in a park, toward concerted instrumental music. A brass band is expected to be primarily rhythmic, to play mainly street or dance music with rat-a-ta-tat of drums or trip of waltz. It is very difficult with a mere band of wind instruments to play what we may call good music to such an audience, although technically it can be rendered very well. The same crowd will welcome a much better kind of music from an orchestra. The fact has been lately shown in Philadelphia, when last summer a band of wind instruments recruited from the Philadelphia Orchestra, aided by a municipal subvention, gave concerts on the plaza in the center of the city. The excellence of the initial programs met with almost no encouragement from the audience or from the municipal officials. And yet at the same time the people were crowding the trolley cars to hear the suburban orchestral concerts at Willow Grove, where a full symphony program was frequently rendered. The argument seems strong on the side of the orchestra, where it is practicable. It is quite true that stringed instruments are less effective and more sensitive than wind in the open air. But what is needed is, if not a building, at least a roof, as at Willow Grove, and that is needed even with a band, for permanent use. 
It really seems that nothing is to be gained by employing a brass band, at least from the standpoint of education or edification. The real enthusiasm not the first rhythmical thrill or itch of the foot as with an orchestra, is plentifully shown in places like Ocean Grove. There is a growing thirst for the best music throughout the ranks of the people in America to-day that it were stupid to ignore and criminal to discourage. To the teacher of music it is of the commonest experience that while the idle rich support the opera, the least essential of the larger forms of music, it is from the poor and from persons of very limited means that comes the best response to serious concerts as well as the most elevated study of the art itself. There is gathered about the institution in Ocean Grove, with its chorus, orchestra and organ, a spirit and an enthusiasm for higher things that is of incalculable value in the cultivation of the people. Valuable, to be sure, are such festivals as the one annually held at Worcester, Mass., but they are short in duration and correspondingly limited in their influence.

As regards the form of our public music it seems that the orchestra is the best for concerted performance. In connection with this it is well to use for solo playing the members of the orchestra when at hand. Similarly singers can most effectively be recruited for extended arias or for ballads; in the latter case they seem to lure the more ignorant listeners to the gradual perception of the best instrumental music. It must not be forgotten that all solo performance has the virtue of affording an example to the listener and of stirring an impulse for the best of all modes of musical enjoyment in individual performance.

A large organ is of value in any ambitious place, as in an institution like Ocean Grove; less for solo performance than for the accompaniment of choruses in oratorios. Moreover, once the organ has been acquired, it needs but a single performer, though its effect is for some purposes comparable to an orchestra. If we seem thus to have settled the matter of the mode of music to the exclusion of the brass band, we cannot dismiss the latter in returning to the question of refreshments in connection with music in public parks. One explanation of the German's tolerance of vacuous music in summer may lie in the fondness for the accompanying eating and drinking.

The difference between the band and the orchestra in relation (388) 
to the matter of refreshments is strange and striking. Brass music somehow goes naturally with feasting and promenading, with an accompaniment of clattering of plates and rattling of dishes. During a symphony nobody thinks but of listening intently. But play a waltz or a military march and the German naturally craves his glass of beer.

This does not come from the mere association of symphonies with respectable academies of music; it has a deeper ground. I remember a restaurant in Munich where a few musicians were employed during the evening. While we were attacking our dinner one of the men began to play upon a mere upright piano a lengthy, little known piece of Schumann's simply, sincerely and effectively. We all naturally stopped eating and listened to the end with undivided attention.

People will go, to be sure, to eat and drink where good musicians are engaged. But inevitably the players will provide the slightest kind of music, unless in a moment of inspiration, and then the listeners, if they are capable of responding, will stop eating. It would be quite as reasonable to eat and drink during a sermon in church as during a concert of good music. In brief, then, not merely idealistic theory but experience teaches that good music demands undivided attention, while the other kind suggests some ulterior diversion or recreation.

Our conclusion ought to point not so much in a negative way to the banning of refreshments as by a positive policy to the giving of good music where refreshments will not be needed. It is not so much an exclusion of refreshments that seems the better plan as a dissociation of them from musical enjoyment. For it cannot be too clearly stated that to provide good music and refreshments at the same time and place defeats the purpose of each.

The experiment of the Boston Symphony Orchestra at its "pop" concerts in summer time might possibly be cited to the contrary. But the general testimony seems to be that they have not been successful from the musical standpoint. When the writer was present though, to be sure, they were specially "popular" occasions, the noise prevented any serious enjoyment or performance.

It seems excellent that refreshments should be provided in public parks; they are the natural element in the open-air recreation of the people; and it is certainly not the purpose of this article to 
advocate their prohibition. The conjunction of the two subjects in the title of this paper suggests the consideration of the relation of the two to each other. They are both needed, but the wisdom of their association is questioned. A practical solution would seem to be to provide refreshments at such a distance from the place of the concert that the clatter of dishes and glasses will not affect the sound of the music. Thus, those persons who wanted to listen intelligently could do so undisturbed, while those who wanted mere tinkling accompaniment to their refreshment might indulge themselves without destroying the intrinsic purpose of the music. This condition exists successfully at Willow Grove, Pa. The whole subject of refreshments in public places varies greatly with national character and conditions. The glass of beer in the public gardens of Germany has a place in the national economy which is difficult for Americans to understand. It is hard for us to perceive its innocuous, nay, its beneficial, influence when not abused or misplaced. In such stretches of public domain as are to be found in the Thuringian Forest, the Black Forest or the Harz Mountains, one passes every afternoon the typical German family enjoying a lengthy walk through romantic scenery. At the turn is a pleasant open-air "Wirthschaft," surrounded by beautiful views, in which each of the family will rest over his glass of beer before starting on the homeward tramp. The excellent German beer is actually a factor of no mean importance in the social life of the people. It is not easy for us to boast of our out-door amusement, baseball, in comparison with such a reasonable form of recreation. The German way of spending the leisure of the day not only rests the nerves and stirs the sense of beauty in landscape; it has the added advantage of furthering the family intercourse.

It seems a desperate hope for us to find here a solution of our national evil of drink. One nation's habits cannot be grafted upon another. Our purpose in suggesting the place that beer holds in German life is to point to the remarkable fact that, even so, beer is seldom or never allowed to intrude in good concerts. On the other hand, it is striking that, as soon as beer is admitted, the music ceases to be worth while.

An American way, on the contrary, is to bring refreshments from home. The picnic is distinctly an American institution. In Germany and generally in Europe there is less reason for the practice 
on account of the low and uniform price of simple refreshments. This habit of ours must count considerably towards dispensing with the need of a public sale of refreshments. Moreover, a lunch carried from home can be consumed with much less disturbance than one that is served with plates; it is treated as a need rather than a diversion, and it will be much less of a hindrance in listening than when one sits formally at a table.

Before stating our conclusion, it may be well to consider a natural objection that will be raised to the use of orchestra: the cost or the difficulty of recruiting it. In reply it may be said that the supply of orchestral players has greatly increased in recent years in America, and the cost is correspondingly diminishing. Every year adds a new name to the list of cities that boast a symphony orchestra. Among the later ones are Seattle and Los Angeles. The winter engagement of a musician is a serious undertaking, for the player is under contract only for the active season of the year, and he must be paid a reasonable annual salary.

In summer the orchestral player, like most musicians, is idle. He can then be employed at more moderate terms than he could afford to take during the winter. The summer orchestra in America would thus have the benefit of the large number of players temporarily out of employment. Moreover, by engaging them during the summer the great cause of symphony concerts in the winter season would be effectively advanced.

The individual members of an orchestra are usually solo players. A certain number of solo performances could be agreed upon in the terms of engagement; this would greatly add to the charm and value of the concert.

Singers could be employed at comparatively small expense. It might be well to try the English plan of engaging less well-known singers for ballads rather than for the extended aria-instead of giving way to the unfortunate rage for "stars" that prevails in America.

It is necessary to provide a building of some kind protected from the weather. An excellent provision is a large auditorium, merely roofed over, with a semicircular covered stage for the players. The absence of a restaurant from the immediate neighborhood of the concert will leave a much larger seating capacity. At a sufficient distance a restaurant could be established where the diners 
might enjoy the distant sounds without disturbing the enjoyment of the actual listeners. It would not be necessary to prohibit eating in the seats of the auditorium, and smoking might be permitted where there are no walls. ${ }^{1}$

In the Queen's Hall concerts, in London, the practice is successfully maintained (indoors) of allowing smoking in all parts of the house. 